\title{
Alterations in Plasma Levels of Amino Acids after Intracerebroventricular Administration of L-Serine or D-Serine in Conscious and Freely Moving Rats
}

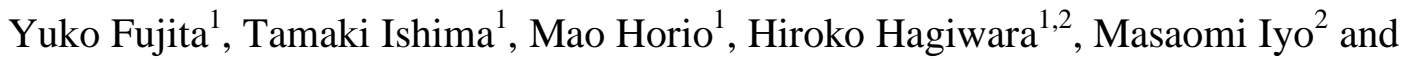 \\ Kenji Hashimoto, ${ }^{1, *}$ \\ ${ }^{I}$ Division of Clinical Neuroscience, Chiba University Center for Forensic Mental Health, Chiba 260-8670, Japan, and \\ ${ }^{2}$ Department of Psychiatry, Chiba University Graduate School of Medicine, Chiba 260-8670, Japan
}

\begin{abstract}
L-Serine has a role in cellular proliferation, being a precursor for protein synthesis, and is also important for brain development. D-Serine plays a role as the endogenous co-agonist at the glycine site on the N-methyl-D-aspartate (NMDA) receptors in the brain. Accumulating evidence suggests that abnormality of D-serine levels might be involved in the pathophysiology of schizophrenia. Using the automated blood sampling system, we examined whether or not intracerebroventricular (icv) infusion of L- and D-isomers of serine could affect plasma levels of amino acids in conscious and freely moving rats. The icv infusion of L-serine significantly decreased the plasma levels of glycine, glutamate, and Dserine, but not glutamine and L-serine. Furthermore, the icv infusion of D-serine significantly decreased the plasma levels of glycine, glutamate, and L-serine, but not glutamine. Expectedly, a marked increase of plasma D-serine was detected after icv infusion of D-serine. These findings suggest that the metabolic pathway for L- and D-serine may be markedly different in the rat brain.
\end{abstract}

\section{INTRODUCTION}

Several lines of evidence suggest that a dysfunction in the glutamatergic neurotransmission via N-methyl-Daspartate (NMDA) receptors might be involved in the pathophysiology of neuropsychiatric diseases, including schizophrenia, mood disorders, Alzheimer's disease, and autism [19]. Amino acids, including glutamate, glutamine, glycine, Lserine, and D-serine, have been shown to be associated with the glutamatergic neurotransmission via NMDA receptors [10]. Previously, we reported alterations in the blood levels of these amino acids in patients with schizophrenia, Alzheimer's disease and autism [11-14]. Thus, we considered that it would be of great interest to examine the potential use of the blood levels of these amino acids as biological markers for neuropsychiatric diseases..

L-Serine has been shown to play a role in cellular proliferation, as it is a precursor for nucleotide synthesis [15-17]. In addition, after the first reports of serine deficiency disorders (3-phosphoglycerate dehydrogenase (3-PGDH) deficiency and 3-phosphoserine phosphatase (3-PSP) deficiency)), it also became clear that L-serine and L-serinederived metabolites are important for brain development and function [17-25]. In contrast, D-serine, an isomer of Lserine, plays a role as a key co-agonist for NMDA receptors [26-32]. D-Serine is produced by serine racemase (SRR) from L-serine, and D-serine has been shown to be metabolized by D-amino acid oxidase (DAAO) in the brain. Several

*Address correspondence to this author at the Division of Clinical Neuroscience, Chiba University Center for Forensic Mental Health, 1-8-1 Inohana, Chiba 260-8670, Japan; Tel: +81-43-226-2147; Fax: +81-43-226-2150; E-mail: hashimoto@faculty.chiba-u.jp reports have demonstrated that abnormality of D-serine levels might be implicated in the pathophysiology of schizophrenia [6-8,11,12,33-36].

Thus, it may be of great interest to study the metabolic pathways of L- and D-serine in the brain. In addition, it would also be of interest to investigate how brain levels of L- and D-serine can affect blood levels of amino acids associated with the NMDA receptors. In the present study, we used an automated blood sampling system to examine whether intracerebroventricular (icv) infusion of L- and Dserine can alter the plasma levels of amino acids (glutamate, glutamine, glycine, L-serine, and D-serine) in conscious and freely moving rats.

\section{MATERIALS AND METHODS}

Animals

Male Sprague-Dawley rats (7 weeks old) weighing 180 $200 \mathrm{~g}$ were purchased from Charles-River Japan (Tokyo, Japan). Rats were housed in clear polycarbonate cages $(22.5 \times 33.8 \times 14.0 \mathrm{~cm})$ at 2 or 3 rats per cage under a controlled 12/12-h light-dark cycle (lights on from 7:00 AM to 7:00 PM), with room temperature at $23 \pm 1{ }^{\circ} \mathrm{C}$ and humidity at $55 \pm 5 \%$. The rats were given free access to water and food pellets. The experimental procedure was approved by the Animal Care and Use Committee of Chiba University Graduate School of Medicine.

\section{Materials}

D-Serine, L-serine, glycine, glutamate, and glutamine were purchased from Sigma-Aldrich Corporation (St. Louis, 
MO). Acetonitrile $\left(\mathrm{CH}_{3} \mathrm{CN}\right)$ and methanol of HPLC grade were purchased from Wako Pure Chemical Co., Ltd. (Tokyo, Japan). Other drugs were purchased from commercial sources.

\section{Operation}

Rats were anaesthetized with sodium pentobarbital (40 $\mathrm{mg} / \mathrm{kg}$, i.p.) and were implanted with a probe that was cemented in place in the cerebroventricular space (coordinates: from the bregma (in $\mathrm{mm}$ ), $\mathrm{AP}=-0.8, \mathrm{ML}=+1.4, \mathrm{DV}=-3.6$ ) [37]. Rats were allowed to recover from the surgery overnight. After recovery, D-serine $(1.0 \mathrm{~mol} / \mathrm{L})$ or L-serine $(0.5$ $\mathrm{mol} / \mathrm{L})$ in an artificial cerebrospinal fluid $(147 \mathrm{mmol} / \mathrm{L}$ $\mathrm{NaCl}, 4 \mathrm{mmol} / \mathrm{L} \mathrm{KCl}$, and $2.3 \mathrm{mmol} / \mathrm{L} \mathrm{CaCl}_{2}$ ) was infused at a flow rate of $5.0 \mu \mathrm{L} / \mathrm{min}$ for $20 \mathrm{~min}$. ICV infusion of 1.0 $\mathrm{mol} / \mathrm{L} \mathrm{L}$-serine caused rats to experience severe seizure, and to die shortly thereafter. Therefore, a half dose $(0.5 \mathrm{~mol} / \mathrm{L})$ of L-serine was used. The automated blood sampling system DR-II (Eicom Co. Ltd., Kyoto, Japan) (Fig. 1) has been applied for blood sampling in conscious and freely moving rats. Three fractions were collected every $30 \mathrm{~min}$ to obtain control (baseline) levels of amino acids. Then five fractions were collected every $30 \mathrm{~min}$ after icv infusion of L- or Dserine.

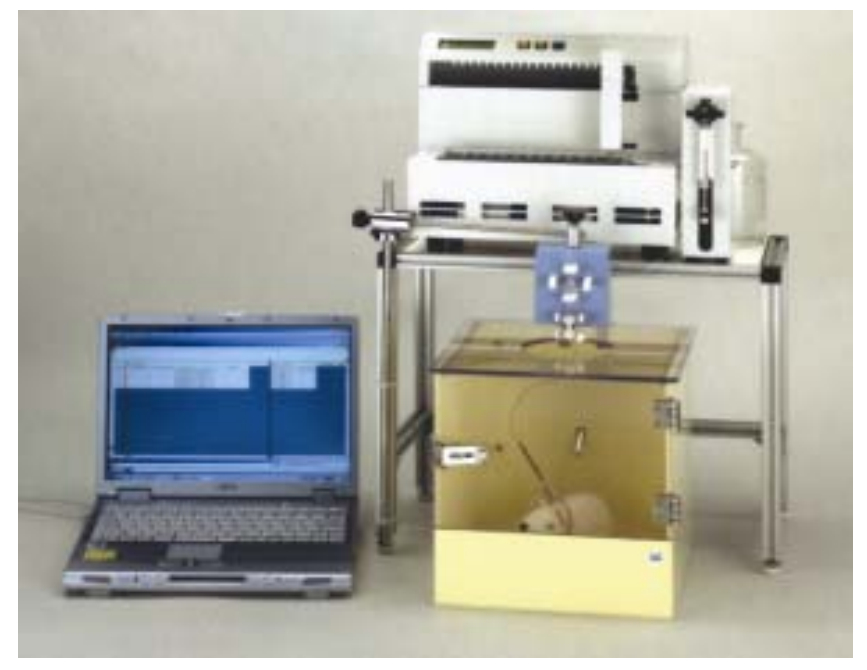

Fig. (1). The automated blood sampling system DR-II.

\section{Measurement of Plasma Amino Acids}

Measurement of the levels of glycine, glutamate, glutamine, D-serine and L-serine was carried out as described in previous studies [38,39] using a high performance liquid chromatography (HPLC) system (Shimadzu Corporation, Kyoto, Japan) with fluorescence detection. Briefly, $20 \mu \mathrm{L}$ of plasma sample was homogenized in $180 \mu \mathrm{L}$ of methanol (HPLC grade) on ice. The homogenates were centrifuged at $4500 \times \mathrm{g}$ for $10 \mathrm{~min}$, and $20 \mu \mathrm{L}$ of the supernatant was evaporated to dryness at $40^{\circ} \mathrm{C}$. To the residue, $20 \mu \mathrm{L} \mathrm{H} \mathrm{H}_{2} \mathrm{O}$ (HPLC grade), $20 \mu \mathrm{L}$ of $0.1 \mathrm{M}$ borate buffer ( $\mathrm{pH} 8.0$ ), and $60 \mu \mathrm{L}$ of $50 \mathrm{mmol} / \mathrm{L}$ 4-fluoro-7-nitro-2,1,3-benzoxadiazole (NBD-F; Tokyo Kasei Kogyo Co., Ltd., Tokyo, Japan) in $\mathrm{CH}_{3} \mathrm{CN}$ (HPLC grade) were added. The reaction mixture was then heated at $60^{\circ} \mathrm{C}$ for $2 \mathrm{~min}$, and immediately supplemented with $100 \mu \mathrm{L}$ of $\mathrm{H}_{2} \mathrm{O} / \mathrm{CH}_{3} \mathrm{CN}$ (90/10) containing
$0.1 \%$ trifluoroacetic acid (TFA) to stop the reaction. A $20 \mu \mathrm{L}$ aliquot of the resultant solution was injected into the HPLC system. Fluorescence detection was performed at $530 \mathrm{~nm}$ with an excitation wavelength at $470 \mathrm{~nm}$.

\section{Statistical Analysis}

Data are expressed as the mean \pm standard deviation (SD). Statistical analysis was performed by one-way analysis of variance (ANOVA) and post hoc Dunnett test. Values of $p$ less than 0.05 were considered statistically significant.

\section{RESULTS}

The icv infusion of L-serine $(0.5 \mathrm{~mol} / \mathrm{L}, 5.0 \mu \mathrm{L} / \mathrm{min}$ for $20 \mathrm{~min}$ ) significantly decreased plasma levels of D-serine, glycine, and glutamate. In contrast, plasma levels of L-serine and glutamine were not altered by icv infusion of L-serine (Fig. 2).

The icv infusion of D-serine $(1.0 \mathrm{~mol} / \mathrm{L}, 5.0 \mu \mathrm{L} / \mathrm{min}$ for $20 \mathrm{~min}$ ) significantly decreased plasma levels of L-serine, glycine, and glutamate (Fig. 2). In contrast, plasma levels of $\mathrm{D}$-serine were markedly (more than 80 -fold) increased by icv infusion of D-serine. Plasma levels of glutamine were not altered by icv infusion of D-serine (Fig. 2).

\section{DISCUSSION}

Using the automated blood sampling system DR-II, we were able to successfully measure the plasma levels of amino acids in conscious and freely moving rats. Therefore, this system would be useful for determination of the blood levels of endogenous substances as biological markers in animal models and the blood levels of drugs for pharmacokinetic studies [40-42].

In this study, icv infusion of L-serine significantly decreased the plasma levels of glycine, glutamate, and Dserine, but not glutamine and L-serine. The mechanism(s) underlying the reduction of the plasma levels of these amino acids after icv infusion of L-serine are currently unclear. Unexpectedly, we found that plasma L-serine levels were not altered after icv infusion of L-serine. In the metabolic pathway of L-serine, L-serine is converted to phospholipids (serine palmitoyltransferase: SPT), phosphoglycerides (phosphatidylserine synthase: PSS), glycine (serine hydroxymethyltransferase: SHMT), and D-serine (serine racemase: SRR)[19] (Fig. 3). Therefore, it is likely that L-serine is rapidly metabolized to other amino acids or undergoes protein synthesis, because the plasma levels of L-serine were not affected by icv infusion of L-serine.

In this study, we found that plasma levels of D-serine were markedly increased after icv infusion of D-serine, suggesting that elevated plasma D-serine may be due to washout from the brain. At the ultrastructural level, D-serine staining appears patchy, and is most abundant around the blood vessels in the forebrain [43]. Furthermore, other studies have reported that there were no changes of D-serine levels in the forebrains of mice lacking DAAO [44,45], suggesting that DAAO does not regulate D-serine levels in the forebrain, where the NMDA receptors are abundant $[7,8]$. Moreover, icv infusion of D-serine significantly decreased plasma levels of glycine, glutamate, and L-serine in the present study, although the mechanism(s) underlying the reduction of the 
ICV Infusion of D-Serine

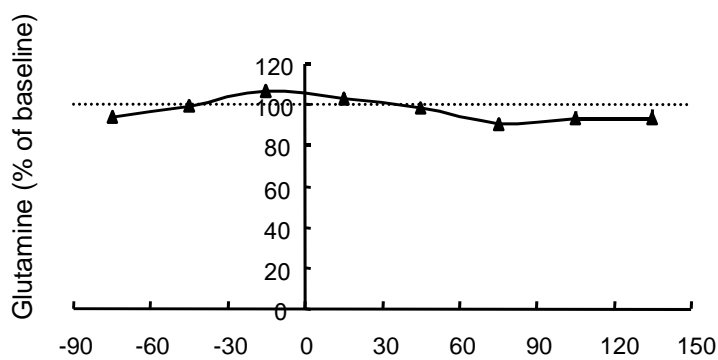

Time after icv administration of D-serine (min)
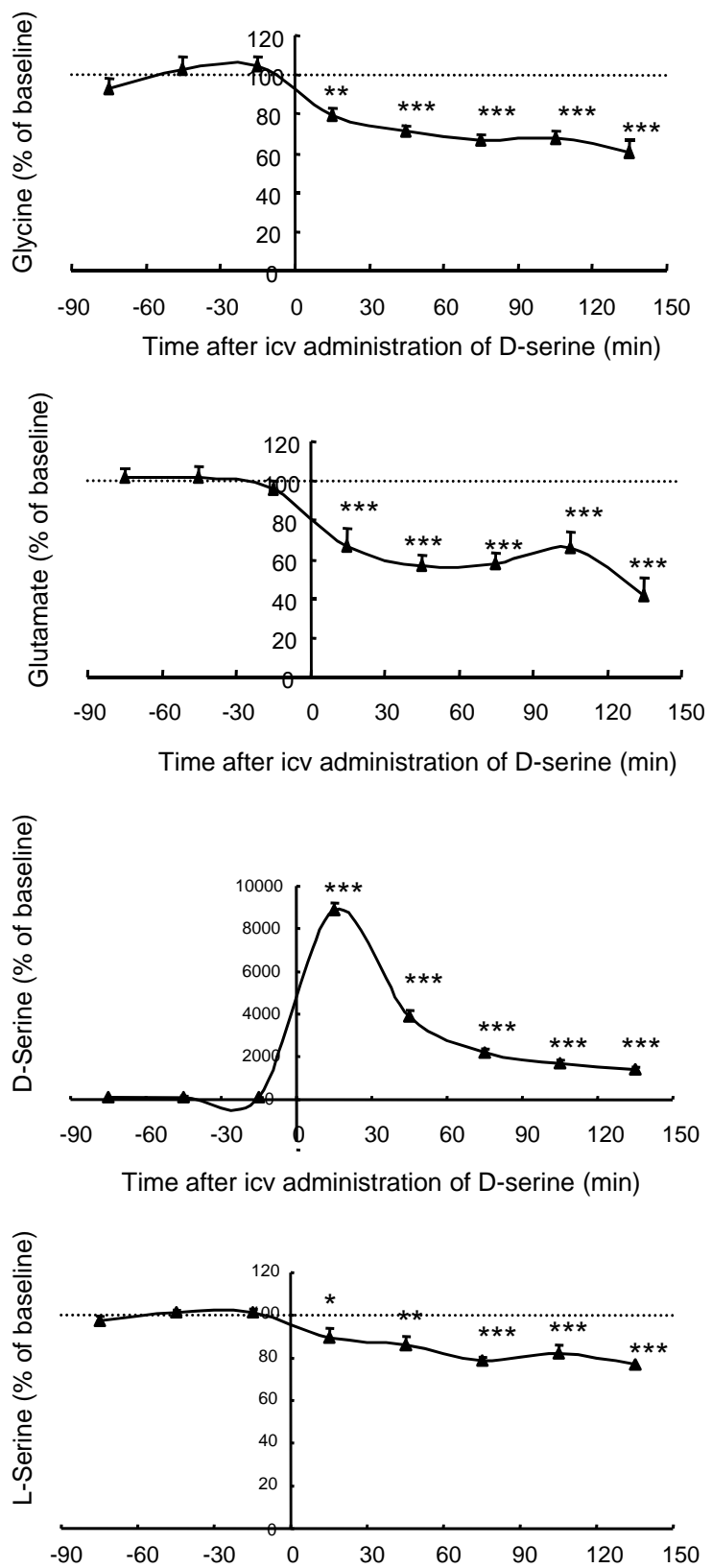

Time after icv administration of D-serine (min)
ICV Infusion of L-Serine

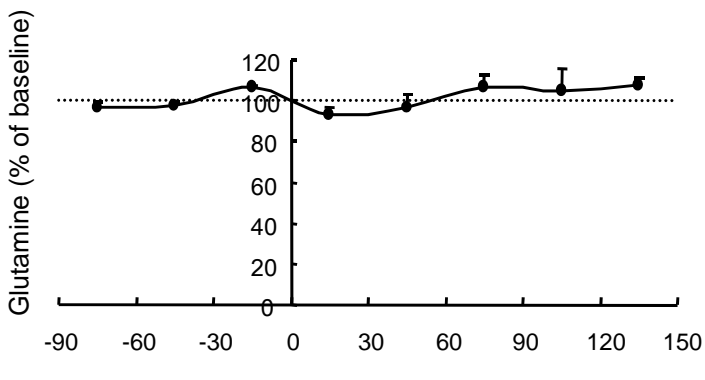

Time after icv administration of L-serine (min)
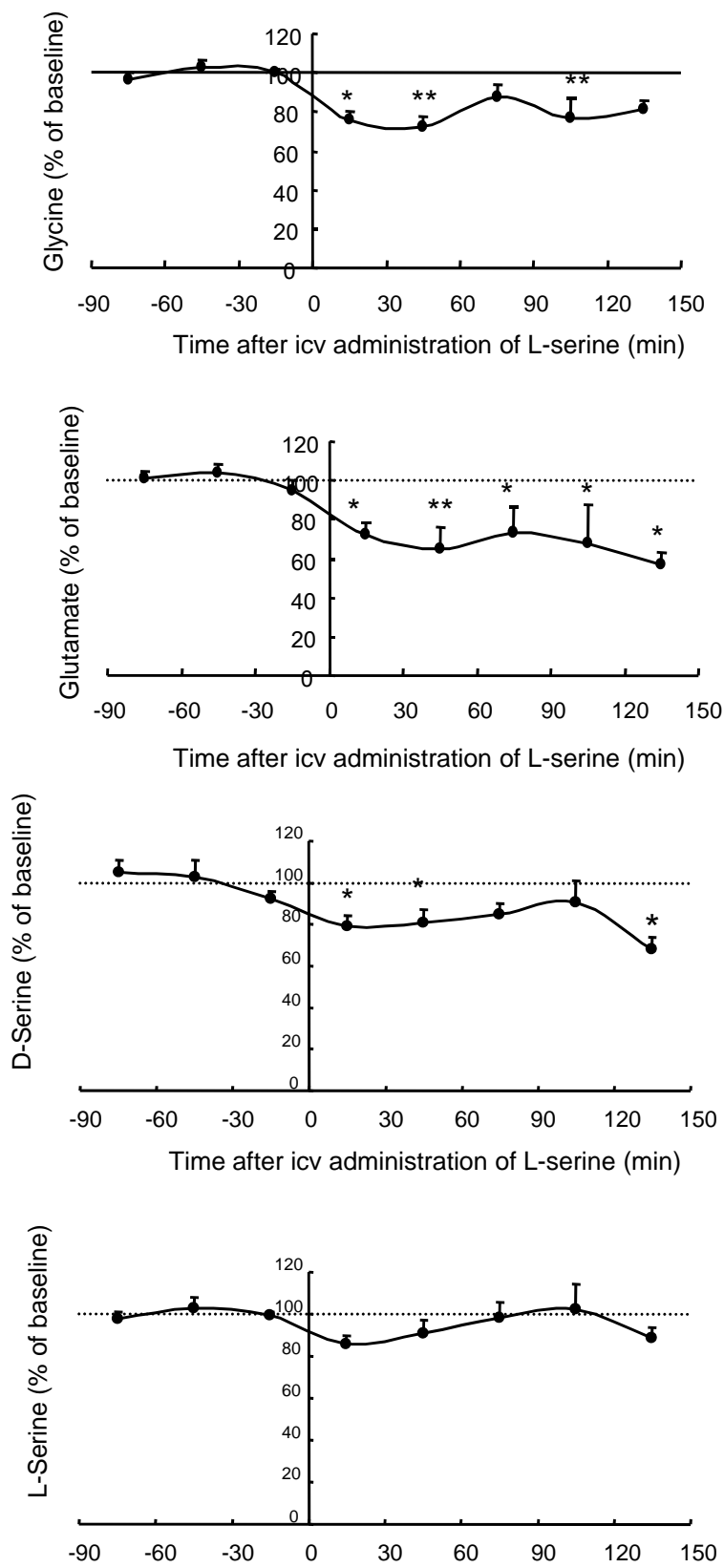

Time after icv administration of L-serine (min)

Fig. (2). Effects of icv infusion of L- and D-serine on rat plasma levels of amino acids. The data were shown as the percentage of control (baseline: before icv administration) values (glutamate: $5.42 \mu \mathrm{M}$, glycine: $30.4 \mu \mathrm{M}$, glutamine: $217 \mu \mathrm{M}, \mathrm{D}$-serine: $1.61 \mu \mathrm{M}$, L-serine: 208 $\mu \mathrm{M}$ (mean of total 13 rats). The data were the mean $\pm \mathrm{SD}$ of 6 (L-serine group) or 7 (D-serine group) rats. $* \mathrm{p}<0.05, * * \mathrm{p}<0.01, * * * \mathrm{p}<0.001$ (vs. baseline). 
plasma levels of these amino acids after icv infusion of Dserine are currently unclear. Further detailed studies will be needed to determine these mechanisms.

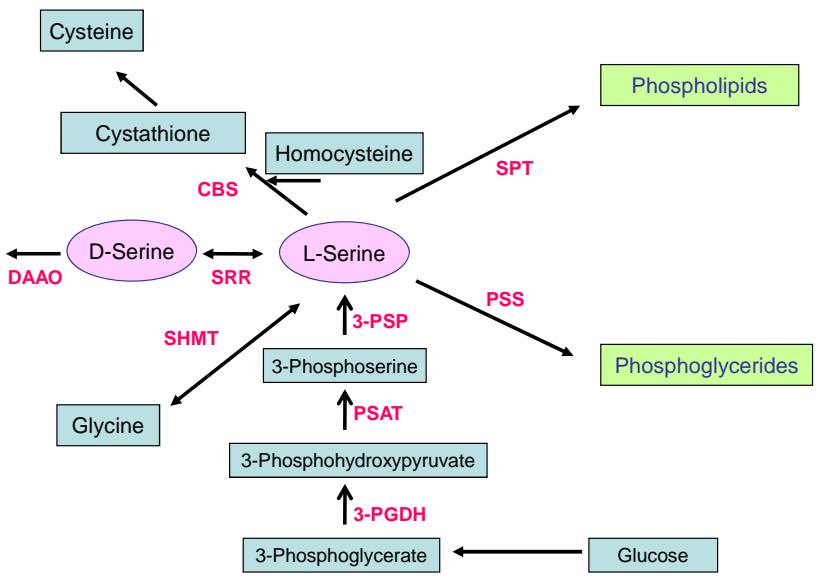

Fig. (3). Proposed pathways of L- and D-serine utilization in the brain. CBS: Cystathionine $\beta$-synthase; DAAO: D-amino acid oxidase; 3-PGDH: 3-Phosphoglycerate dehydrogenase; PSAT: Phosphoserine aminotransferase; 3-PSP: 3-Phosphoserine phosphatase; PSS: Phosphatidylserine synthase; SHMT: serine hydroxymethyltransferase; SPT: Serine palmitoyltransferase; SRR: Serine racemase.

\section{CONCLUSIONS}

The present preliminary findings suggest that the metabolic pathways for L- and D-serine in the brain might be different, although further detailed studies are needed. In addition, our results indicate that the automated blood sampling system would be useful for determining the blood levels of endogenous substances as biological markers in several animal models and the blood levels of drugs in pharmacokinetic studies in conscious and freely moving rats.

\section{ACKNOWLEDGEMENTS}

This study is partly supported by a grant from the Ministry of Education, Culture, Sports, Science, and Technology of Japan (to K.H.).

\section{ABBREVIATIONS}

$\begin{array}{ll}\text { CBS } & =\text { Cystathionine } \beta \text {-synthase } \\ \text { DAAO } & \text { D-Amino acid oxidase } \\ \text { NMDA } & =\text { N-Methyl-D-aspartate } \\ \text { 3-PGDH } & \text { 3-Phosphoglycerate dehydrogenase } \\ \text { PSAT } & =\text { Phosphoserine aminotransferase } \\ \text { 3-PSP } & =3 \text {-Phosphoserine phosphatase } \\ \text { PSS } & =\text { Phosphatidylserine synthase } \\ \text { SHMT } & =\text { Serine hydroxymethyltransferase } \\ \text { SPT } & =\text { Serine palmitoyltransferase } \\ \text { SRR } & =\text { Serine racemase }\end{array}$

\section{REFERENCES}

[1] Javitt, D.C.; Zukin, S.R. Am. J. Psychiat., 1991, 148, 1301-1308.

[2] Olney, J.W.; Farber, N.B. Arch. Gen. Psychiat., 1995, 52, 9981007.

[3] Goff, D.C.; Coyle, J.T. Am. J. Psychiat., 2001, 158, 1367-1377.

[4] Sawa, A.; Snyder, S.H. Science, 2002, 296, 692-695.

[5] Goff, D.C.; Coyle, J.T. Annu. Rev. Pharmacol. Toxicol., 2002, 42, 165-179.

[6] Hashimoto, K.; Okamura, N.; Shimizu, E.; Iyo, M. Curr. Med. Chem - CNS Agents, 2004, 4, 147-154.

[7] Hashimoto, K.; Shimizu, E.; Iyo, M. Curr. Psychiat. Rev., 2005, 1, 151-163.

[8] Hashimoto, K.; Hattori, E. In.; Neurogenet. Psychiat. Disorders; Akira Sawa and Melvin G. McInnis, Ed.; Informa Healthcare, New York, 2007, 81-100.

[9] Snyder, S.H.; Ferris, C.D. Am. J. Psychiat., 2000, 157, 25-30.

[10] Hashimoto, K.; Sawa, A.; Iyo, M. Biol. Psychiat., 2007, 62, 13101316.

[11] Hashimoto, K.; Fukushima, T.; Shimizu, E.; Komatsu, N.; Watanabe, H.; Shinoda, N.,; Nakazato, M.; Kumakiri, C.; Okada, S.; Hasegawa, H.; Imai, K.; Iyo, M. Arch. Gen. Psychiat., 2003, 60, 572576.

[12] Yamada, K.; Ohnishi, T.; Hashimoto, K.; Ohba, H.; IwayamaShigeno, Y.; Takao, H.; Toyota, T.; Minabe, Y.; Nakamura, K.; Shimizu, E.; Itokawa, M.; Mori, N.; Iyo, M.; Yoshikawa, T. Biol. Psychiat., 2005, 57, 1493-1503.

[13] Hashimoto, K.; Fukushima, T.; Shimizu, E.; Okada, S.; Komatsu, N.; Okamura, N.; Koike, K.; Koizumi, H.; Kumakiri, C.; Imai, K.; Iyo, M. Prog/ Neuropsychopharmacol. Biol. Psychiat., 2004, 28, 385-388.

[14] Shinohe, A.; Hashimoto, K.; Nakamura, K.; Tsujii, M.; Iwata, Y.; Tsuchiya, K.J.; Sekine, Y.; Suda, S.; Suzuki, K.; Sugihara, G.; Matsuzaki, H.; Minabe, Y.; Sugiyama, T.; Kawai, M.; Iyo, M.; Takei, N.; Mori, N. Prog. Neuropsychopharmacol. Biol. Psychiat., 2006, 30, 1472-1477.

[15] Snell, K. Adv. Enzyme. Regul., 1984, 22, 325-400.

[16] Hirabayashi, Y.; Furuya, S. Prog. Lipid Res., 2008, 47, 188-203.

[17] de Koning, T.J.; Snell, K.; Duran, M.; Berger, R.; Poll-The BT.; Surtees, R. Biochem. J., 2003, 371(Pt 3), 653-661.

[18] de Koning, T.J. Curr. Opin. Neurol., 2004, 17, 197-204.

[19] de Koning, T.J. J. Inherit. Metab. Dis., 2006, 29, 347-351.

[20] de Koning, Duran M, Dorland, L. Gooskens, R.; Van Schaftingen, E.; Jaeken, J.; Blau, N.; Berger, R.; Poll-The BT. Ann. Neurol., 1998, 44, 261-265.

[21] Klomp, L.W.; de Koning, T.J.; Malingré, H.E., van Beurden, A.; Brink, M.; Opdam, F.L.; Duran, M.; Jaeken, J.; Pineda, M.; Van Maldergem, L.; Poll-The BT, van den Berg, I.E.; Berger, R. Am. J. Hum. Genet., 2000, 67, 1389-1399.

[22] de Koning, T.J.; Klomp, L.; van Oppen, A.C.; Beemer, F.A.; Dorland, L.; van den Berg, I.; Berger, R. Lancet, 2004, 364, 22212222.

[23] Jaeken, J,; Detheux, M.; Van Maldergem, L.; Frijns, J.P.; Alliet, P.; Foulon, M.; Carchon, H.; Van Schaftingen, E. J. Inherit. Metab. Dis., 1996, 19, 223-226.

[24] Jaeken, J.; Detheux, M.; Van Maldergem, L.; Foulon, M.; Carchon, H.; Van Schaftingen, E. Arch. Dis. Child, 1996, 74, 542-545.

[25] Jaeken, J.; Detheux, M.; Fryns, J.P.; Collet, J.F.; Alliet, P.; Van Schaftingen, E. J. Med. Genet., 1997, 34, 594-596.

[26] Hashimoto, A.; Oka, T. Prog. Neurobiol., 1997, 52, 325-353.

[27] Schell, M.J. Philos. Trans. R. Soc. Lond B. Biol. Sci., 2004, 359, 943-964.

[28] Diamond, J.S. Cell, 2006, 125, 639-641.

[29] Martineau, M.; Baux, G.; Mothet, J.P. Trends Neurosci., 2006, 29 , 481-491.

[30] Wolosker, H. Sci. STKE, 2006, 2006: pe41.

[31] Wolosker, H. Mol. Neurobiol., 2007, 36, 152-164.

[32] Halassa, M.M.,;Fellin, T.; Haydon, P.G. Trends Mol Med., 2007, 13, 54-63.

[33] Hashimoto, K.; Engberg, G.; Shimizu, E.; Nordin, C.; Lindström, L.H.; Iyo, M. Prog. Neuropsychopharmacol. Biol. Psychiat., 2005, 29, 767-769.

[34] Bendikov, I.; Nadri, C.; Amar, S.; Panizzutti, R.; De Miranda, J.; Wolosker, H.; Agam, G.A. Schizophr. Res., 2007, 90, 41-51.

[35] Madeira, C.; Freitas, M.E.; Vargas-Lopes, C.; Wolosker, H.; Panizzutti, R. Schizophr. Res., 2008, in press. 
[36] Burnet, P.W.; Hutchinson, L.; von Hesling, M.; Gilbert, E.J.; Brandon, N.J.; Rutter, A.R.; Hutson, P.H.; Harrison, P.J. Schizophr. Res., 2008, in press.

[37] Paxinos, G.; Watson, C. The Rat Brain in Stereotaxic Coordinates - The New Coronal Set, Fifth Edition, Academic Press, New York, 2004.

[38] Hashimoto, K.; Engberg, G.; Shimizu, E.; Nordin, C.; Lindström, L.H.; Iyo, M. BMC Psychiat., 2005, 5, 6.

[39] Fukushima, T.; Kawai, J.; Imai, K.; Toyo'oka, T. Biomed. Chromatogr., 2004, 18, 813-819.

[40] Lin, L.C.; Yang, K.Y.; Chen, Y.F.; Wang, S.C.; Tsai, T.H. J. Chromatogr. A, 2005, 1073, 285-289.
[41] Wang, S.C.; Ho, L.K.; Yen, J.V.; Tsai, T.H. Biomed. Chromatogr., 2006, 20, 911-916

[42] Ferraris, D.; Duvall, B.; Ko, Y.S.; Thomas, A.G.; Rojas, C.; Majer P.; Hashimoto, K.; Tsukamoto, T. J. Med. Chem., 2008, in press.

[43] Schell, M.J.; Brady, R.O.; Jr.; Molliver, M.E.; Snyder, S.H. J. Neurosci., 1997, 17, 1604-1615.

[44] Hashimoto, A.; Nishikawa, T.; Konno, R.; Niwa, A.; Yasumura Y.; Oka, T.; Takahashi, K. Neurosci. Lett., 1993, 152, 33-36.

[45] Morikawa, A.; Hamase, K.; Inoue, T.; Konno, R.; Niwa, A.; Zaitsu, K. J. Chromatogr. B Biomed. Sci. Appl., 2001, 757, 119-125.

(C) Fujita et al.; Licensee Bentham Open.

This is an open access article distributed under the terms of the Creative Commons Attribution License (http://creativecommons.org/licenses/by/2.5/), which permits unrestrictive use, distribution, and reproduction in any medium, provided the original work is properly cited. 